\title{
A PERFORMANCE NA ESCOLA: EVIDENCIANDO LIMITES E POSSIBILIDADES
}

Isabella Fernanda Santos

Recebido em 30/06/2017

Aprovado em 03/09/2017 


\begin{abstract}
A Arte é um componente curricular da Educação Básica brasileira e seu ensino/aprendizagem contempla inúmeras expressões artísticas da Dança, do Teatro, das Artes Visuais e da Música. A performance é uma expressão artística muito relevante e recorrente na contemporaneidade e se insere nas lógicas das artes pública e conceitual, podendo ampliar a aproximação entre público e arte, assim como o cruzamento de diversas outras expressões contemporâneas. O ensino/aprendizagem da performance na escola é um desafio, pois evidencia diversas questões e problemas em relação a métodos de ensino/aprendizagem e organização escolar na atualidade. Pensar o corpo como suporte para a arte traz à tona inúmeras questões relevantes para a arte contemporânea, questões que devem ser levadas para as aulas de Arte. Este artigo apresenta e discute algumas experiências com a performance no ensino/aprendizagem de Arte em uma escola pública. Essas práticas se relacionam diretamente com a poética do artista/professor e levantam questionamentos sobre as tensões existentes entre arte e ensino/ aprendizagem. Como a performance e a arte contemporânea se apresentam na escola? Quais são suas possibilidades e limitações nesse contexto? Como repensar tempo e espaço escolar tendo em vista a complexidade artística da contemporaneidade?
\end{abstract}

Palavras-Chave: Ensino de arte. Performance. Ensino de performance.

\title{
INTRODUÇÃO
}

$\mathrm{M}$

inhas experiências como artista/professora dizem muito sobre minhas vivências pessoais e sobre meu processo de criação. São experiências que se atravessam. Este artigo apresenta e discute experiências em produção artística e ensino/aprendizagem de Arte tendo em vista que elas se cruzam e dialogam a todo momento em minha prática. É difícil identificar os limites entre essas duas práticas, pois elas se complementam constantemente. Este artigo trata da desconstrução de limites entre produção artística e metodologias de ensino/aprendizagem, bem como da flexibilização dos limites da escola - limites de tempo, espaço e métodos.

Em relação às experiências com arte na escola, trato ensino e aprendizagem como práticas imbricadas e indissociáveis - entendendo que é importante pensar em como se dá a aprendizagem em Arte e a construção do pensamento artístico para desenvolver uma metodologia consistente e significativa nesse processo. Dessa maneira, uso os dois termos imbricados: ensino/aprendizagem.

O objetivo deste artigo é levantar discussões sobre o ensino/aprendizagem de performance na escola, considerando os atravessamentos entre produção artística e prática docente e levantando possibilidades de ações significativas no espaço escolar. As experiências com performance viven- 
ciadas por mim e pelos meus alunos se relacionam, especialmente, com a Abordagem Triangular de Ana Mae Barbosa e com o conceito de ambiência, desenvolvido por diversos autores, entre eles Lucia Pimentel (2015) e Fernando Deoud (2005).

Contextualização, fruição e fazer artístico são as ações sistematizadas conjuntamente na Abordagem Triangular. Desenvolvida por Barbosa desde a década de 1980, representa um embasamento muito importante para a construção de metodologias em ensino/aprendizagem de Arte. Desde a sua primeira publicação, essa proposta vem sendo apropriada e revisitada por diversos autores e professores de Arte. Tal abordagem consiste, na articulação entre estabelecer relações estéticas, críticas, históricas, conceituais, entre outras, conhecer e ter contato com obras de arte e produzir objetos artísticos.

O conceito de ambiência ultrapassa as noções físicas de sala ambiente, assim como o tempo escolar e a disponibilidade de materiais nas aulas de Arte, considerando todos os fatores que impactam a construção de conhecimentos. Pimentel (2015) define ambiência como "o conjunto de fatores físicos e intelectuais que interferem nas ações de seus componentes. É o 'lugar' onde se pode estruturar, desenvolver e expressar ideias e pensamentos. É o que se tem de mais próximo como campo de ação" (PIMENTEL, 2015). Esse conceito extrapola a ideia de espaços físicos e da sala ambiente para as aulas de arte, entendendo que o processo de ensino/aprendizagem é mais subjetivo e complexo, pois abarca fatores diversos em sua dinâmica.

São referências para essa pesquisa, trabalhos de performers brasileiros, especialmente Berna Reale (1965) e Paulo Nazareth (1977), assim como textos de outros artistas e pesquisadores que tratam performance e arte contemporânea. Reale e Nazareth foram escolhidos porque são artistas brasileiros que pesquisam questões raciais e de gênero em seus processos de criação, questionando o próprio mercado de arte, entre outros temas.

\section{TRAJETÓRIA E QUESTÕES DE UMA ARTISTA/PROFESSORA}

erto dia, em um evento de rua, eu disse a um amigo que eu não cabia mais no desenho. Ele me olhou como se dissesse "Sua herege!" e afirmou: "A gente nunca abandona o desenho". Acho que a gente abandona algumas coisas temporariamente, outras para sempre. No meu caso, foi uma questão de me abrir para novas experimentações artísticas, entre elas, a performance. E, nesse sentido, não estou mais cabendo, apenas, no desenho. Esse é um processo recente em minha prática artística e que vem ganhando mais sentido a cada experiência com a performance. 
Além da possibilidade de potencializar a expressividade e me apropriar de novas maneiras de produzir, tenho entendido a performance como um lugar de afeto e encontro. Talvez essa impressão tenha se dado porque meu primeiro trabalho foi realizado em parceria com uma amiga e foi muito significativo. As parcerias entre artistas - e o encontro desses corpos - me parecem muito fluidos e naturais na performance, especialmente quando penso em minha trajetória com desenho e ilustração, cuja relação se dava apenas entre mim e o objeto. Talvez essa necessidade de trabalhar coletivamente e construir parcerias tenha surgido ao mesmo tempo em que a performance surgiu no meu processo criativo. São muitas perguntas e possibilidades que instigam minha produção.

Minha primeira performance, em parceria com outra artista, foi realizada há dois anos. Como culminância de um processo de diálogos e trocas, pensamos uma ação performativa de rua. Essa experiência foi muito afetiva e teve como conceitos os questionamentos da mulher diante dos padrões culturais e comportamentais impostos pela sociedade patriarcal, em especial aqueles que se ligam aos ideais de beleza e às ideias de feminino e feminilidade. Desde então, tenho pesquisado a performance em meu processo de criação e também sua relação com o ensino/aprendizado de Arte. Só foi possível incluir essa expressão artística de forma consistente em minhas aulas quando comecei a produzir, estabelecendo diálogos entre minhas vivências de artista, professora e pesquisadora.

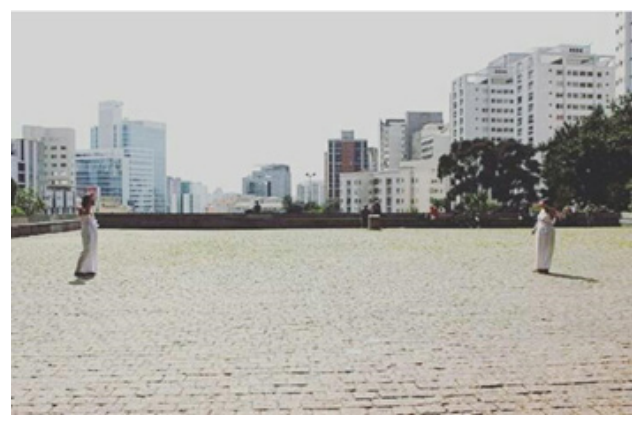

FIGURA 1: Performance realizada em parceria com outra artista. Acervo da artista (2015).

Segundo Eleonora Fabião (2009, p. 64), na performance "a matéria a ser trabalhada é a própria vida. O oficio do performer seria o de 'transformar a vida' [...] ou ainda, o modo como a vida pode ser vivida. O performer é aquele que evidencia e potencializa a mutabilidade do vivo." Assim, a performance se deu para mim como algo necessário no que diz respeito à sua potencialidade expressiva e à apropriação do corpo e do gesto, como 
uma nova etapa em meus processos de criação. Os caráteres autobiográfico e afetivo da performance parecem fazer ainda mais sentido quando pensados coletivamente, seja através de minhas parcerias com outros artistas ou em sala de aula.

Foi durante o mestrado que fiz outras parcerias inesperadas que me levaram a pensar o meu corpo por outro viés, como matéria e suporte no processo criativo. Foi uma surpresa conviver com amigas da dança e do teatro em diversos momentos - quando elas se espremiam em pequenos espaços ou saiam "performando" pelas calçadas do campus. Essas brincadeiras, onde eu era quase sempre espectadora, me estimularam a explorar o meu corpo em novas experimentações artísticas.

A partir dessa parceria, desenvolvemos coletivamente uma performance durante um congresso de arte/educadores no ano de 2015. O trabalho levantava questões e tensões envolvidas na relação entre produção artística e prática docente, entre elas a necessidade de o professor de Arte produzir artisticamente e a valorização da licenciatura em arte. A tensão entre produção e docência sempre esteve presente no meu trabalho, especialmente nos últimos anos, e ainda mais após a conclusão do mestrado em ensino de artes.

A construção da metodologia do artista/professor pode ser considerada um processo de criação, pois o mesmo faz experimentações a todo o momento testando métodos e escolhendo as melhores maneiras de alcançar os objetivos estabelecidos. Essas ações podem configurar outro tipo de poética - que é diferente da poética do processo de criação artística - pois o artista/professor desenvolve uma linha de trabalho através dessas experiências diárias. As duas poéticas - metodologia de ensino e processo de criação artístico - se atravessam continuamente. As duas se complementam e se influenciam.
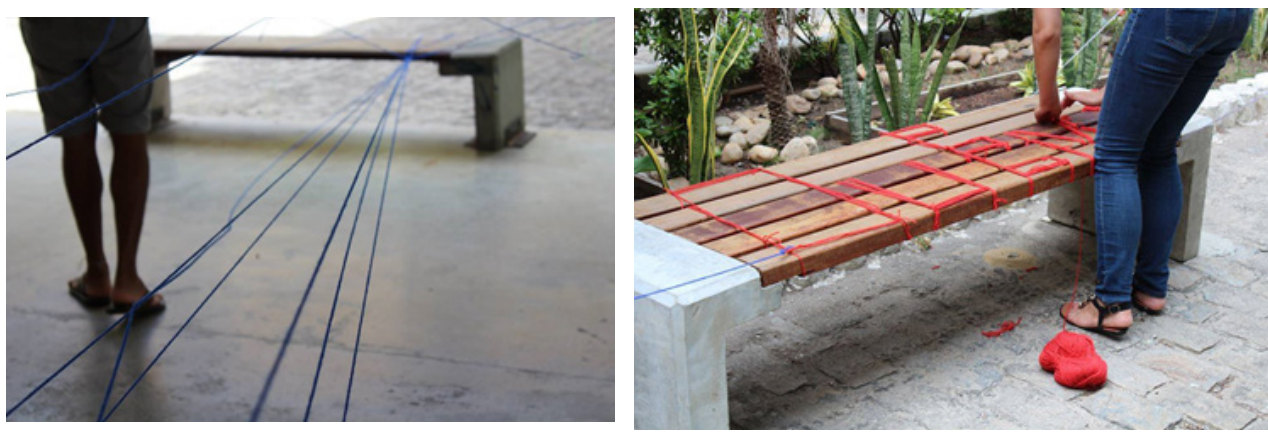

FIGURAS 2 e 3 - Performance desenvolvida em parceria com outros artistas. Acervo da artista (2015). 


\section{PERFORMANCE E ARTE CONTEMPORÂNEA:} REFERÊNCIAS PARA OS PROCESSOS CRIATIVOS

performance foi reconhecida como forma de expressão indepen-
dente na década de 1970 juntamente com o desenvolvimento da
arte conceitual, seguindo a tendência de combater o tradicionalismo na arte e dar forma e corpo a diversos conceitos envolvidos na criação artística (GOLDBERG, 2006). Desde então, é cada vez maior o número de artistas que pesquisam a performance e desenvolvem experimentações nas quais o corpo é o suporte e até mesmo o conceito.

É pela natureza transgressora da performance que sua presença se faz ainda mais necessária na escola e em espaços públicos. Mesmo que a arte contemporânea traga em seu discurso a pretensão de aproximar as pessoas das obras, ainda é preciso construir uma identificação do público em geral com esse tipo de arte, através de apresentações em espaços mais acessíveis e experiências em ensino/aprendizagem de Arte que contemplem essa expressão. Desde seu surgimento, a performance ganha cada vez mais espaço na arte contemporânea e se insere na lógica da arte pública, extrapolando os limites de museus e galerias de arte e assim assumindo, muitas vezes, o papel de algo que aproxima público e obra, arte e vida. Ainda, segundo Goldberg (2006),

A performance tem sido um meio de dirigir-se diretamente a um grande público, bem como de chocar plateias, levando-as a reavaliar suas concepções de arte e sua relação com a cultura. Por outro lado, o interesse do público por esse meio de expressão artística, particularmente na década de 1980, provém de um aparente desejo desse público de ter acesso ao mundo da arte, de tornar-se expectador de seus rituais e de sua comunidade distinta, de deixar-se surpreender pelas apresentações inusitadas, sempre transgressoras, que caracterizam as criações desse artistas (GOLDBERG, 2006, p. 08).

Mesmo que a afirmação se refira a outro contexto da história da arte, as ações performativas ainda mantêm o caráter transgressor, ocupando espaços variados, com a possibilidade de ampliar o alcance do público. Berna Reale e Paulo Nazareth são artistas que apresentam seus trabalhos em espaços públicos e questionam concepções já construídas em relação ao mercado, valor e lugar da arte. Tenho esses dois artistas como referências no meu trabalho como artista/professora - especialmente os trabalhos de Reale por discutir também questões de gênero e reafirmar o posicionamento político ${ }^{1}$ da mulher na arte contemporânea.

1 Considero arte política como aquela que pode transformar as percepções sobre a vida e sobre a realidade, provocando o público e convidando-o a resignificar. Regina Silveira (2010) afirma que "Toda arte é política, no sentido em que transforma a percepção do espectador". 
s experiências com performance no ensino/aprendizagem de Arte apresentadas neste artigo se deram com turmas de nonos anos do Ensino Fundamental em uma escola da Rede Municipal de Ensino de Belo Horizonte. Optei por inserir a performance de uma forma mais incisiva - e prática - como conteúdo do nono ano. Esses alunos possuem, aproximadamente, quatorze anos de idade, e já desenvolveram certa autonomia para a realização de tais práticas. Em turmas de sextos a oitavos anos a performance também é trabalhada, mas de maneira mais superficial e breve, mais voltada para a fruição do que para o fazer artístico.

O estudo da performance com os alunos das turmas de nono ano se deu a partir dos eixos corpo político, corpo híbrido e corpo e espaço. Inicialmente, apresentei alguns artistas para os alunos, finalizando esse recorte em dois deles: Berna Reale e Paulo Nazareth. Os trabalhos artísticos que têm o corpo como suporte demandam pensar o espaço escolar de maneira diferenciada. É preciso pensar quais são os espaços disponíveis para esse tipo de prática, assim como a ressignificação desses espaços. Dessa forma, a inserção da performance na escola traz à tona diversas questões sobre os métodos utilizados no processo de ensino/ aprendizagem e sobre a educação na contemporaneidade.

A escola onde atuo apresenta uma estrutura tradicional no que diz respeito à organização de tempos, espaços e currículo. Nesse sentido, introduzir a performance nas aulas de Arte por si só já representa uma ação transgressora que evidencia diversas questões acerca do processo de ensino/aprendizagem e da organização escolar como um todo. Possibilitar o estudo dessa expressão artística e o desenvolvimento do pensamento artístico através de atos performativos demanda relativização dos espaços para que o corpo não seja negligenciado em toda sua potencialidade expressiva e gestualidade.

A fotografia reproduzida abaixo é o registro de uma experiência cujo eixo trabalhado foi o corpo híbrido. Essa ação se deu na garagem da escola e foi realizada em grupo. Disponibilizei materiais diversos, como tecidos e fibras, para que os alunos pudessem experimentar variados espaços da escola se misturando a eles e se camuflando na paisagem. A apropriação de diversos espaços, assim como a utilização de materiais 
inusitados é uma característica bastante presente nas manifestações artísticas contemporâneas. Esses aspectos precisam ser contemplados no ensino/aprendizagem de Arte.
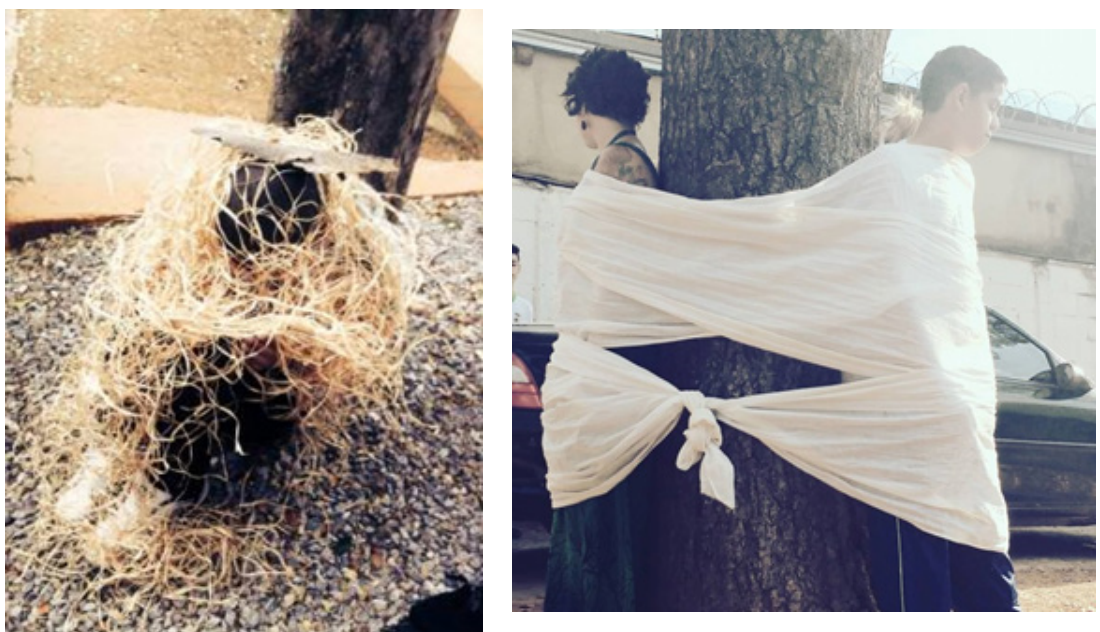

FIGURAS 4 e 5 - Experiências com o eixo corpo híbrido. Acervo da artista (2015).

O estudo da arte contemporânea e da performance no ensino/aprendizagem de Arte deve abranger fazer artístico, contextualização e fruição Abordagem Triangular - para que os alunos possam vivenciar experiências mais significativas e complementares, compreendendo, ainda, os mecanismos envolvidos nos processos de criação. Essas três ações se complementam a todo momento e não há hierarquia entre elas. Fruição e contextualização, por exemplo, possibilitam o aumento do repertório imagético e de referências para que os alunos possam criar seus próprios trabalhos artísticos pensando corpo e espaço de forma mais poética.

O eixo corpo político foi trabalhado através de várias práticas, reforçando a ideia de arte política e de arte como denúncia e forma de sensibilização do público para inúmeras questões sociais e culturais. O trabalho da artista paraense Berna Reale vem ao encontro dessa proposta, pois suas performances tratam da violência, especialmente da violência contra a mulher. A ação registrada na fotografia a seguir tratou dos padrões de beleza impostos na sociedade contemporânea, discutindo também o conceito de beleza, sempre presente na história da arte. 


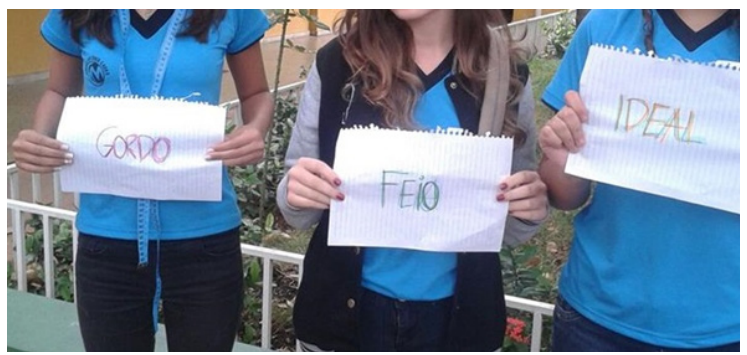

FIGURA 6: Experiências com o eixo corpo político. Acervo da artista (2015).

Antes de explorar a performance, as turmas envolvidas nessas práticas estudaram diversos artistas que produzem obras de cunho político, assim como diversas correntes e tendências artísticas que trouxeram denúncias e críticas através de seus produtos. A desconstrução do ideal de beleza na arte - ligado ao classicismo e à arte acadêmica - fez parte do processo de ensino/aprendizagem em anos anteriores. Sou a única professora de Arte nesta escola. Assim, praticamente todos os alunos envolvidos nessas práticas foram meus alunos desde o sétimo ano, o que possibilita que haja um trabalho contínuo e processual com o grupo.

O último eixo trabalhado pelas turmas foi corpo e espaço. A intenção com essa ação foi utilizar o corpo de maneiras diferentes das convencionais na escola. Os alunos estiveram em lugares que normalmente não são ocupados por eles, seus corpos foram utilizados para preencher espaços vazios e mudar a configuração desses espaços. Ocupar lugares antes não ocupados na escola, ou ocupar esses espaços me maneiras diferentes do usual, produzindo artisticamente, pode ser considerada, por si só, uma atitude política e crítica, no sentido de questionar a estrutura escolar e o sistema em que esses alunos estão inseridos. Muitas vezes, os três eixos se atravessavam, tendo como objetivo a produção de trabalhos que discutiam questões sociais e culturais, assim como o funcionamento do próprio espaço escolar.

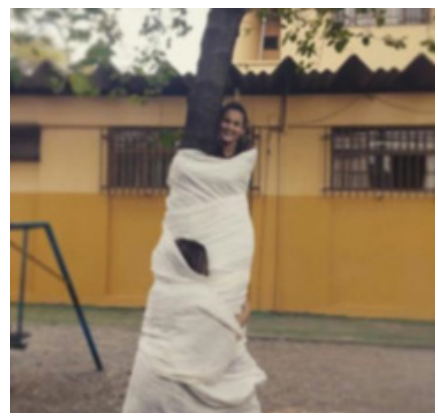

FIGURA 7: Experiências com o eixo corpo e espaço. Acervo da artista (2015). 


\section{EXPLODINDO LIMITES: ESPAÇOS PERMITIDOS E ESPAÇOS CRIADOS}

$\mathrm{P}$ ude perceber que o envolvimento dos alunos em atividades com a performance foi muito maior do que quando trabalhamos expressões e técnicas artísticas mais tradicionais, como o desenho, por exemplo. Para eles, a performance é novidade, pois questiona a relação entre corpo e escola no momento em que possibilita que se apropriem de forma diferenciada dos espaços. Eles se sentem mais livres e à vontade para experimentar e até mesmo para propor ações.

A sala de aula é apenas um dos espaços que pode ser utilizado nas aulas de Arte. É importante ampliar espaços e flexibilizar tempos para a realização das práticas artísticas na escola, especialmente quando há um uso mais expressivo do corpo e do gesto. O espaço da escola tradicional, muitas vezes, ainda é bastante formatado e entende-se, comumente, que as atividades devem acontecer em tempos e espaços pré-determinados. Cabe aos professores considerarem esses aspectos para a proposição de atividades mais significativas para os alunos.

Ao se tomar como pressuposto a tese de que a aprendizagem é um fenômeno ao mesmo tempo individual e social, que se produz pelo compartilhamento e pelo diálogo entre sujeitos como processos de apropriação de significados, fica evidente que a efetividade da ação educativa está mais relacionada com condições subjetivas de interlocução que os sujeitos elaboram com outros sujeitos e com o mundo do que com construções de currículos lineares ou com formas engessadas de organização dos tempos e dos espaços de aprendizagem propostos objetivamente pelos atuais currículos escolares (THIESEN, 2011).

O conceito de ambiência amplia essa noção, pois considera que existem diferentes espaços e tempos para o ensino/aprendizagem, pois o mesmo não se dá apenas na escola ou na sala de aula. São vários os fatores que influenciam esse processo. Todos os elementos, objetos, sons, cheiros etc. que estão presentes durante a aula impactam na construção do conhecimento. Essa construção, por sua vez, não cessa ao final das aulas quando bate o sinal e todos vão para casa. Em um contexto onde a internet está cada vez mais presente no cotidiano de crianças e jovens, torna-se ainda mais possível ampliar esses tempos e espaços de ensino/aprendizagem. 


\section{CONSIDERAÇÕEs Finais}

7 xperimentar a performance na escola, e mais especificamente nesta escola bastante tradicional e cuja estrutura ainda é a mesma de séculos atrás, traz à tona diversas questões e provocações. Numa dessas experiências, me surpreendi com a coordenadora chamando a atenção de um aluno que estava subindo em uma árvore durante a prática. A ação do aluno era coerente com a proposta apresentada para a turma. Independente disso foi inevitável o estranhamento da coordenadora diante de tal atitude. Não é comum - o que causa estranhamento - que os alunos circulem livremente no espaço escolar e experimentem esse espaço de maneiras diferentes do que está posto.

Quantas vezes os alunos recuam ao serem advertidos por outros educadores, quando são surpreendidos pelos mesmos nesses espaços? Quantas vezes tenho de justificar que os alunos estão produzindo e não perambulando pelos espaços? Quantas vezes me pergunto quais são os limites que devo impor? Quais são os limites que realmente fazem sentido? Qual é o lugar do corpo na escola?

Repensar a aprendizagem em Arte na contemporaneidade implica revisitar tempos passados, repensá-los, buscando compreender quais seus contextos e heranças, com vistas a melhor entender o contexto contemporâneo e identificar as possibilidades de atuação educativa em Arte. A partir das ambiências presentes, na atualidade, no contexto das artes e do que se considera ser o campo da educação, são levantados pontos de discussão para que se considere a importância do ensino/aprendizagem de Arte na ambiência escolar (PIMENTEL, 2015, p. 6).

É preciso repensar as práticas, criar registros, refletir sobre as estratégias escolhidas no processo de ensino/aprendizagem. A escola, porém, muitas vezes, parece alheia a todas as mudanças que se apresentam na contemporaneidade. Tempos e espaços escolares se mantêm da mesma forma que foram organizados há muito tempo. A arte parece deslocada nesse contexto. Como se dá o ensino/aprendizagem de Arte nesse contexto? Se o corpo é entendido como suporte e meio de expressão artística, é preciso repensar a relação entre corpo e escola. A ideia de ambiência faz com que revisemos o espaço escolar, numa perspectiva 
mais atual e pós-moderna que contempla as inovações tecnológicas e as novas formas de se aprender.

É preciso pensar o que a escola faz com o corpo e como a arte se coloca nesse espaço. Qual é o papel do artista/professor nesse espaço? Como trabalhar arte e performance na escola? É importante dizer que atualmente muitas escolas têm sido pensadas fora desse padrão, mas, no Brasil, a grande maioria das instituições de ensino ainda mantém características muito tradicionais que estão em dissonância com as mudanças que vem ocorrendo desde o final do século XX em diversas áreas do conhecimento e na cultura, de maneira geral. Ainda assim, muitas escolas continuam funcionando, seguindo modelos mais conservadores e rígidos no que tange ao currículo e ao seu funcionamento. É preciso voltar o olhar para essa questão, pensando sobre como é possível criar estratégias mais significativas no ensino/aprendizagem de Arte nesses espaços e, ainda, em possíveis reconfigurações dessas estruturas. 


\section{REFERÊNCIAS}

BARBOSA, Ana Mae. Arte-Educação no Brasil. São Paulo: Perspectiva, 1978.

BARBOSA, Ana Mae, CUNHA, Fernanda Pereira da (orgs.). A abordagem triangular no ensino das artes e culturas visuais. São Paulo: Cotez, 2010.

DEOUD, Fernando. Arte: Ambiência Estética, Imaginativa e Metafórica. Dissertação de Mestrado em Artes, EBA/UFMG, 2005.

GOLDBERD, RoseLee. A arte da performance: do futurismo ao presente. Martins Fontes: São Paulo, 2006.

FABIÃO, Elenora. Performance, teatro e ensino: poéticas e políticas da interdisciplinaridade. In: TELLES, Narciso; FLORENTINO, A. (Org.). Cartografias do ensino do teatro. Uberlândia: EDUFU, 2009-a. p. 61-72.

NAZARETH, Paulo. In: ENCICLOPÉDIA Itaú Cultural de Arte e Cultura Brasileira. São Paulo: Itaú Cultural, 2017. Disponível em: $<$ http://enciclopedia.itaucultural.org.br/pessoa425936/paulo-nazareth $>$. Acesso em: 30 jun. 2017. Verbete da Enciclopédia.

PIMENTEL, Lucia Gouvêa. Fugindo da escola do passado: arte na vida. Revista Digital do LAV - Santa Maria - vol. 8, n. 2, p. 5 - 17. - mai./ago.2015ISSN 1983 - 7348. Disponível em:<http://dx.doi.org/10.5902/1983734819862> Acesso em 15 set. 2017.

PIMENTEL, Lucia Gouvêa. Novas territorialidades e identidades culturais: o ensino de arte e as tecnologias contemporâneas. In: Anais do $20^{\circ}$ Encontro da Associação Nacional de Pesquisadores em Artes Plásticas / Sheila Cabo Geraldo, Luiz Cláudio da Costa (organizadores). - Rio de Janeiro: ANPAP, 2011. Disponível em: <http://www.anpap.org.br/anais/2011/ pdf/ceav/lucia_gouvea_pimentel.pdf> Acesso em 28 jun. 2015.

SILVEIRA, Regina. Politica e arte: ocupação de Regina Silveira. Disponível em: <http://www.itaucultural.org.br/politica-e-arte-ocupacao-regina-silveira-2010> Acesso em 16 set. 2017.

THIESEN, Juares da Silva. Tempos e espaços na organização curricular: uma reflexão sobre a dinâmica dos processos escolares. Educação em revista (Faculdade de Educação da Universidade Federal de Minas Gerais). Belo Horizonte, 2011. vol. 27, n.1 - abril, 2011 . 